tral feature of this program (just as it was carried out in the 1990s) is a consultative model whereby: (1) new chair attendees prepare a case as prework describing their challenge/problem ${ }_{i}(2)$ the team at MU reviews the case description and brings together necessary resources with the other attendees and faculty ${ }_{i}(3)$ the MU team identifies key people within the institution that the individual new chair chooses for one-on-one consultations learning more about specific issues which may be translatable to his or her own institution or department. While not all problems are solved, participants leave the workshop with a pathway forward and a comforting feeling that their problems are not unique to their environment. They also leave with new relationships that they can call on in the future to help provide advice, expertise, or counsel.

Evaluation from the past 2 workshops provides evidence that resurrecting this workshop is filling an important need. Comments from participants illustrate the critical value of this experience:

- Every new chair would benefit from this. The group size was optimal.

- An outstanding program. I think I benefited from every component, which is quite rare for any conference. The other chairs and the faculty were amazing- supportive, bright and motivated to solve problems on a 'systems' level.

- An excellent program! I feel I know a number of my fellow new chairs in way that would not have been possible without this workshop. We've tackled some tough problems together, and we have a better understanding of the state of family medicine around the country.

- Truly excellent overall...I'm not just saying it. Very well prepared, organized, and implemented. Very much appreciated.

- This program was incredibly valuable to my development as a new chair! The wisdom and knowledge was greatly appreciated! Keep offering it!

The MU workshop is one of several elements of programming which we are offering in ADFM through our Leadership Development Committee. According to a survey of ADFM members last year, $38 \%$ of chairs have had the job for less than 3 years and $26 \%$ anticipate a change in leadership within the next 3 years. In addition to a systematic "welcoming" of new chairs into ADFM through the President, Executive Director and Secretary, our Leadership Development Committee oversees other programming aimed at new family medicine department chairs. These include workshops held at the AAMC meeting and in conjunction with the ADFM Winter meeting, our new chair advisor program, and our developing new chair's toolbox.

Steven Zweig MD, Ardis Davis MSW, Jack Colwill MD and Michael Hosokawa, EdD

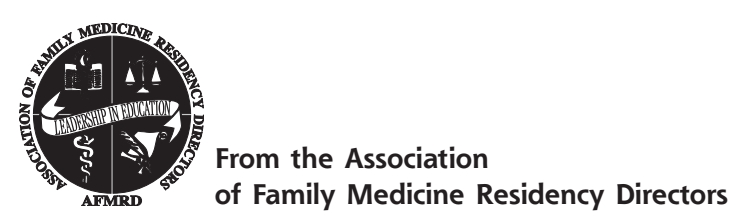

Ann Fam Med 2013;484-485. doi:10.1370/afm.1574..

\section{AFMRD FMCC SCHOLARSHIPS}

Political advocacy is increasingly important in residency education for the next generation of family physicians to learn how to promote health interventions for our patients and our communities; it includes promoting our specialty which most directly addresses these needs. Through political advocacy, residents learn aspects of community health, population management, and leadership to effect change in health systems. The AFMRD will assist family medicine residencies to provide their residents the opportunity to participate in political advocacy by offering annual scholarships to the Family Medicine Congressional Conference (FMCC) held every May.

Sponsored by the AAFP and the Council of Academic Family Medicine (CAFM), the FMCC educates participants about the fundamentals of advocacy, the legislative process, and up-to-date information about current priorities for family medicine and our patients. Residents then receive practical, hands-on experience by engaging legislators in these issues, powerfully sharing their experience and inspiring change. Alongside family medicine leaders, residents learn how to be effective in Washington DC and at home.

Since 2011, the AFMRD has offered 10 scholarships each year for residents to attend the FMCC. Comments from scholarship winners include:

"... the FMCC experience taught me that there is much more I can do about inequalities in health care than I thought. I am now a part of the solution." Christina Chavez-Jobnson MD, University of California at San Francisco, Fresno

"Our patients' health, and the equity and stability of our health care system, depend on all of us doing our share ... the first step begins with you!" Lauren S. Hughes, MD, MPH, University of Washington Department of Family Medicine

"We need to be heard for the protection of our profession, our patients, [and] our health." Elizabeth Lynn, MD, Soutb Nassau Communities Hospital Family Medicine Residency

"Attending the FMCC was a great learning experience, but more importantly it rekindled my passion for the field of family medicine." Jeanine Spielberger, MD, Banner Good Samaritan Family Medicine

The AFMRD plans to continue to sponsor resident scholarships for $\$ 1,500$ each to help cover travel and 
FMCC conference costs. The call for applications occurs in the fall each year. Applications require a Program Director letter of support, the candidate's statement of interest, and completion of the STFM On-line Advocacy Course. The deadline for applications is in December with announcement of winners in January. Selection of resident scholarship winners from across the country is based upon their commitment to legislative advocacy. The selection committee also makes efforts to select a group of winners that represents geographic diversity. Scholarship winners will be invited to attend a function during the conference to meet other awardees and will be required to submit a report afterwards, including a presentation of their experience to their home program.

AFMRD is committed to providing opportunities to teach leadership and advocacy. We hope you will take advantage of this opportunity by encouraging residents to apply. Finally, based on the large pool of enthusiastic applicants we received in the last 2 years, there is a clear need and desire for more resident participation in this conference. The AFMRD encourages programs to not only promote this opportunity, but to consider using local resources to create more scholarships to support resident attendance.

Karen Mitchell, MD, Lisa Maxwell, MD

Brian Crownover, $M D_{i}$ Grant Hoekzema, $M D_{i}$

Nathan Krug, MD, Michael Mazzone, $M D_{i}$

$W$. Fred Miser, $M D_{i}$ Stephen Scbultz, $M D_{i}$

Todd Shaffer, MD, MBA, Michael Tuggy, MD

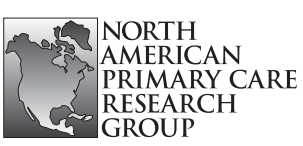

From the North American

Primary Care Research Group

Ann Fam Med 2013;485. doi:10.1370/afm.1577.

\section{NAPCRG CONFERENCE SUMMARIES AVAILABLE}

The NAPCRG website is now a resource for researchers and clinicians looking for summaries of conference sessions and workshops. Many sessions from this year's PBRN Conference and the 2012 Annual Meeting are now available at http://www.napcrg.org.

Find a special web page devoted to the topic of evaluating practice transformation with content from the 2012 Annual Meeting. There are video clips of interviews with presenters and summaries of sessions.

Also, an open forum to discuss evaluating practice transformation is available with the opportunity to comment and share with colleagues. Post new informa- tion, provide your experiences, and share resources with fellow researchers.

Click on the conference web page for the summaries and resources.

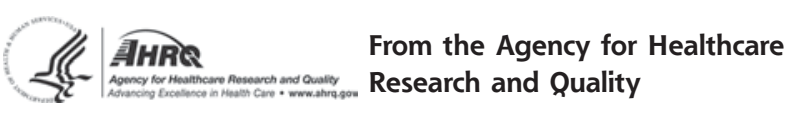

Ann Fam Med 2013;485-486. doi:10.1370/afm.1579.

\section{AHRQ UPDATES ON PRIMARY CARE RESEARCH: MULTIPLE CHRONIC CONDITIONS RESEARCH NETWORK}

Almost one-third of all Americans-and $80 \%$ of older Americans-are estimated to have at least 2 or more concurrent chronic conditions that collectively have an adverse effect on health status, function, or quality of life, and that require complex approaches to health care. ${ }^{1,2}$ Treatment for people living with multiple chronic conditions (MCC) accounts for an estimated $71 \%^{1}$ of the Nation's health care costs, and $93 \%$ of Medicare expenditures. ${ }^{3}$ The number of people with MCC is growing, and is expected to continue to grow as the population ages. However, relatively little is known about how to best treat these patients. Most medical research remains focused on single conditions, and clinical care guidelines rarely address comorbid conditions. Adherence to multiple guidelines that each focus on a single condition is often impractical for patients, and treatment for one condition can have negative effects on other conditions. To make matters worse, clinicians are often compensated based on disease-specific performance measures, which may encourage unnecessary, and even potentially harmful, care for patients with MCC.

The Agency for Healthcare Research and Quality (AHRQ) is working to build the evidence base to support better care for people with MCC in support of the Department of Health and Human Services' national Strategic Framework on Multiple Chronic Conditions. ${ }^{4}$ In particular, AHRQ's Improving Primary Care initiative aims to improve health outcomes and quality of life for people with MCC by improving the quality, safety, efficiency, and effectiveness of evidence-based preventive and chronic care services. As part of this effort, AHRQ funded the Multiple Chronic Conditions Research Network to help advance the field of MCC research, provide needed guidance for clinicians and patients, and advise policymakers about improved methods to measure and promote quality care for patients with complex multiple conditions. In 